\title{
O RECONHECIMENTO DA CIDADANIA POR MEIO DAS POLÍTICAS PÚBLICAS DE TRATAMENTO DE CONFLITOS: A BUSCA POR UM NOVO PARADIGMA DE JUSTIÇA A PARTIR DAS RESOLUÇÕES DO CONSELHO NACIONAL DE JUSTIÇA
}

\author{
Francielli Silveira Fortes \\ Universidade de Santa Cruz do Sul - UNISC - Brasil \\ Natália Luiza Fetzer \\ Universidade de Santa Cruz do Sul - UNISC - Brasil
}

\section{Resumo}

O presente artigo tem o intuito de traçar alguns elementos doutrinários específicos sobre a temática do reconhecimento da cidadania por meio das políticas públicas de tratamento de conflitos, considerando para tanto os elementos conformadores da jurisdição estatal. Para tanto a tentativa de construção de um novo paradigma de justiça a partir das Resoluções do Conselho Nacional de Justiça são os vetores estruturantes que apontam a regulação dos meios alternativos de solução de conflitos sociais. Eis que a tentativa construtivista de engendrar os mecanismos receptivos da cidadania e da busca de novos modelos alternativos à jurisdição estatal, são possibilidades democráticas possíveis na sociedade plural e complexa da atualidade.

Palavras-chave: Cidadania. Políticas Públicas. Tratamento de Conflitos.

\section{Considerações Iniciais}

Com o presente artigo, pretende-se analisar o reconhecimento da cidadania por meio das políticas públicas de tratamento de conflitos evitando-se o enfrentamento às demandas judiciais. Para tanto, esses vetores de reconhecimento da cidadania são pautados a partir de um novo paradigma de justiça, em que pese o próprio Conselho Nacional de Justiça (CNJ) vêm exarando resoluções com o intuito de fomentar perspectivas e meios auxiliares na promoção da resolução dos conflitos sociais instaurados atualmente na sociedade brasileira. Assim, o Poder Judiciário desde seu surgimento histórico, até sua crise funcional e os fatores que o levaram a essa situação de desvalorização e ineficiência, apresentando as principais alternativas de Jurisdição e suas características como meios facilitadores das resoluções de conflitos.

O trabalho abordará alguns elementos do surgimento do Poder Judiciário, sua crise atual e as perspectivas de algumas alternativas extrajudiciais para a resolução de conflitos que estão 
surgindo na sociedade contemporânea. Todavia, as demandas existentes, não são mais suportadas pelos sistemas utilizados pelo Judiciário, que além de não acompanhar as tecnologias e as diversas relações oriundas também da globalização. Portanto, a crise no Judiciário, logo fez surgir outras alternativas para a resoluções de conflitos na sociedade, alternativas que não impedem a forma tradicional da jurisdição e óbvio, são legais perante à lei. Esses mecanismos extrajudiciais estão associados à simplicidade e celeridade processual, além de ser informal e ter como objetivo a possível extinção do conflito sem a necessidade de um processo judicial que poderia não extinguir realmente a demanda e prolongar a lide.

O método de abordagem a ser adotado no desenvolvimento do presente estudo será o dedutivo, ou seja, está organizado de modo a partir do geral para o particular, trabalhando-se, inicialmente, categorias essenciais à pesquisa, tais como os aspectos que envolve a, a consciência da cidadania, participação popular e as práticas democráticas, bem como os desafios e particularidades relacionados às ações políticas através das políticas públicas de inclusão social. Este trabalho é fruto da continuidade da pesquisa acadêmica das autoras e tenta traçar alguns apontamentos que servem para o debate de toda a comunidade acadêmica.

\section{Cidadania e Políticas Públicas de tratamento de conflitos: o suporte do Conselho Nacional de Justiça}

É emergente o interesse sobre as políticas públicas no debate cotidiano sobre a política e a vida social; amplos segmentos das sociedades percebem que os assuntos públicos não são simples e que não se resolvem apenas soluções rápidas. O termo política públicas é utilizado com significados algo distintos, com uma abrangência maior ou menor: ora indica um campo de atividade, ora um propósito político bem concreto, ou um programa de ação ou os resultados obtidos por um programa [...] em uma política há sempre uma teia de decisões e ações que alocam (implementam) valores; uma instância que, uma vez constituída, vai conformando o contexto no qual as decisões futuras serão tomadas. (SCHIMIDT; MENEGAZZI,2008, p. 3123)

A política aparece, como uma atividade, isto é, um conjunto organizado de normas e atos tendentes à realização de um objetivo determinado. (COMPARATO, 1997, p. 353) A compreensão de política pública ganha relevo para a Ciência do Direito precisamente no estudo da efetivação dos direitos constitucionais sociais, também chamados de direitos fundamentais de segunda e terceira dimensões. É nesse sentido que se fala de política como programa de ação, que, enquanto tal, política não é uma norma nem um ato, ela se distingue nitidamente dos elementos da realidade jurídica, sobre os quais os juristas desenvolveram a maior parte suas reflexões, desde os primórdios da jurisprudência romana.

Barbarói, Santa Cruz do Sul, Edição Especial n.44, p.<220-237>, jul./dez. 2015 
Pode-se tratar de políticas públicas querendo significar os programas de governo ou planejamento de ação dos órgãos públicos nas mais diversas áreas. Essa segunda acepção difere da primeira. (JORGE NETO, 2009, p.54) Uma coisa é a própria ação, o próprio fazer, o próprio atuar; outra, que lhe antecede, é o programa formal da ação ou o planejamento da atuação estatal. Pois, tratar de política públicas, ora estamos a significar a ação estatal com vista ao atingimento de um fim estatal (especificamente a concretização dos direitos fundamentais); ora estamos a significar o planejamento, o programa, as balizas dessa atuação; ora estamos a significar todo o conjunto de ações, incluídas as ações de planejamento e as ações executivas do atuar estatal.

As políticas públicas repercutem na economia, na sociedade, porque qualquer teoria da política pública precisa também explicar as inter-relações entre Estado, política, economia e sociedade. A abordagem sistêmica evidencia os estreitos liames das políticas com o conjunto dos componentes de um sistema político como instituições, processos, atores, arenas, lideranças, e a cultura política. (SCHIMIDT, 2008, p.2309) A abordagem sistêmica revela que qualquer fenômeno esta abarcado num conjunto complexo de fatores, e que uma teoria geral da política pública implica a busca de sintetizar teorias construídas no campo da sociologia, da ciência política e da economia.

A grandeza do estudo das políticas públicas merece uma compreensão mais profunda, é importante que se entenda o que está previsto nas políticas que o afetam, quem estabeleceu, de que modo foram estabelecidas, como estão sendo implementadas, quais são os interesses em jogo, quais são as principais forças envolvidas, quais são os espaços de participação existentes; há percepção ampla acerca da superficialidade da separação entre política e administração.

Atualmente, observam-se tendências recíprocas de politização da elite burocrática e de burocratização dos políticos. Adquire força a figura do administrador político, com o reconhecimento de que a administração se converteu em um componente integral da estrutura decisória do aparato governamental. É impossível a política sem capacidade administrativa e é ingênuo pensar que possa haver atuação administrativa profissional sem orientação política. (SCHIMIDT, 2008, p.2311)

A manifestação da importância do estudo das políticas públicas merece uma compreensão mais profunda, é importante que se entenda o que está previsto nas políticas que o afetam, quem estabeleceu, de que modo foram estabelecidas, como estão sendo implementadas, quais são os interesses em jogo, quais são as principais forças envolvidas, quais são os espaços de participação existentes. Há percepção ampla acerca da superficialidade da separação entre política e administração.

Barbarói, Santa Cruz do Sul, Edição Especial n.44, p.<220-237>, jul./dez. 2015 
Atenta-se para tendências recíprocas de politização da elite burocrática e de burocratização dos políticos. Ganha força a figura do administrador político, com o reconhecimento de que a administração se converteu em um componente integral da estrutura decisória do aparato governamental. (SCHIMIDT, 2008, p.2318)

No Brasil a trajetória da cidadania é indissociável do processo de desenvolvimento dos direitos humanos. São facetas de uma mesma história da humanidade em busca de aperfeiçoamento das instituições jurídicas e políticas para garantia da liberdade e da dignidade humana (COSTA, 2007). Em verdade é uma história de lutas pelos direitos fundamentais da pessoa, lutas marcadas por massacres, violência, exclusão e outras variáveis que caracterizam o Brasil desde os tempos da colonização e que, na realidade, tem como único fim a conquista de direitos que legitimem o devido exercício da cidadania.

O repertório da cidadania no Brasil está diretamente relacionado ao estudo histórico da evolução constitucional do País. A Constituição imperial de 1824 e a primeira Constituição republicana de 1891 consagraram a expressão cidadania. Mas foi a partir de 1930 que ocorreu uma nítida distinção nos conceitos de cidadania, nacionalidade e naturalidade. Desde então, nacionalidade refere-se à qualidade de quem é membro do Estado brasileiro e o termo cidadania tem sido empregado para definir a condição daqueles que, como nacionais, exercem direitos políticos (COSTA, 2007).

Assim, o Conselho Nacional de Justiça $(\mathrm{CNJ})$ é uma instituição pública que visa aperfeiçoar o trabalho do sistema judiciário brasileiro, principalmente no que diz respeito ao controle e à transparência administrativa e processual. O CNJ tem a missão de contribuir para que a prestação jurisdicional seja realizada com moralidade, eficiência e efetividade em benefício da Sociedade. E sua visão, é ser um instrumento efetivo do Poder Judiciário. Atua na Política Judiciária, zelando pela autonomia do Poder Judiciário e pelo cumprimento do Estatuto da Magistratura, expedindo atos normativos e recomendações.

Sendo a partir da Resolução 125 de 29 de novembro de 2010, que dispôs sobre a Política Judiciária Nacional de tratamento adequado de conflito no âmbito do Poder Judiciário. De acordo com o Art. $7^{\circ}$ da Resolução 125/10, os Tribunais deverão criar, no prazo de 60 (sessenta) dias, Núcleos Permanentes de Métodos Consensuais de Solução de Conflitos, compostos por magistrados da ativa ou aposentados e servidores, preferencialmente atuantes na área, com as seguintes atribuições, entre outras: (Redação dada pela Emenda $n^{\circ} 1$, de 31.01.13) I desenvolver a Política Judiciária de tratamento adequado dos conflitos de interesses, estabelecida nesta Resolução; II - planejar, implementar, manter e aperfeiçoar as ações voltadas ao cumprimento da política e suas metas; III - atuar na interlocução com outros Tribunais e

Barbarói, Santa Cruz do Sul, Edição Especial n.44, p.<220-237>, jul./dez. 2015 
com os órgãos integrantes da rede mencionada nos arts. $5^{\circ}$ e $6^{\circ} ;$ IV - instalar Centros Judiciários de Solução de Conflitos e Cidadania que concentrarão a realização das sessões de conciliação e mediação que estejam a cargo de conciliadores e mediadores, dos órgãos por eles abrangidos; $\mathrm{V}$ - incentivar ou promover capacitação, treinamento e atualização permanente de magistrados, servidores, conciliadores e mediadores nos métodos consensuais de solução de conflitos; VI propor ao Tribunal a realização de convênios e parcerias com entes públicos e privados para atender aos fins desta Resolução. (http://www.cnj.jus.br)

A Resolução 125/10 sofreu alteração com a Emenda 01, no dia 31 de janeiro de 2013, em que alterou os artigos 1o, 2o, 6o, 7o, 8o, 9o, 10, 12, 13, 15, 16, 18 e os Anexos I e III da Resolução $\mathrm{n}^{\circ}$ 125, de 29 de novembro de 2010; bem como instituiu o código de ética de conciliadores e mediadores judiciais. Aos órgãos judiciários incumbe oferecer mecanismos de soluções de controvérsias, em especial os chamados meios consensuais, como a mediação e a conciliação, bem assim prestar atendimento e orientação ao cidadão. O programa será implementado com a participação de rede constituída por todos os órgãos do Poder Judiciário e por entidades públicas e privadas parceiras, inclusive universidades e instituições de ensino. (http://www.cnj.jus.br)

Ainda, conforme expressa o próprio artigo $6^{\circ}$ da Resolução 125/10, para desenvolvimento dessa rede, caberá ao CNJ: (Redação dada pela Emenda $n^{\circ}$ 1, de 31.01.13) I - estabelecer diretrizes para implementação da política pública de tratamento adequado de conflitos a serem observadas pelos Tribunais; II - desenvolver conteúdo programático mínimo e ações voltadas à capacitação em métodos consensuais de solução de conflitos; III providenciar que as atividades relacionadas à conciliação, mediação e outros métodos consensuais de solução de conflitos; IV - regulamentar, em código de ética, a atuação dos conciliadores, mediadores e demais facilitadores da solução consensual de controvérsias; V buscar a cooperação dos órgãos públicos competentes e das instituições públicas e privadas da área de ensino; VI - estabelecer interlocução com a Ordem dos Advogados do Brasil, Defensorias Públicas, Procuradorias e Ministério Público, estimulando sua participação nos Centros Judiciários de Solução de Conflitos e Cidadania; VII - realizar gestão junto às empresas, públicas e privadas, bem como junto às agências reguladoras de serviços públicos; VIII - atuar junto aos entes públicos e grandes litigantes de modo a estimular a autocomposição. (http://www.cnj.jus.br) 


\section{Elementos de formatação do surgimento da jurisdição: pauta histórica}

O Poder Judiciário surgiu da necessidade de regular as relações na sociedade, que com o tempo, começaram a tornar-se mais complexas. No início da humanidade não havia classes sociais e estados, havia apenas nômades que viviam da caça e da pesca. Os conflitos eram resolvidos dentro das comunidades através de suas lideranças, essas comunidades se regulavam pela Lei da força e da vingança privativa, cada um era seu próprio juiz, fazendo valer o que entendia ser seu direito. Entretanto, conforme essas comunidades foram deixando de ser nômades e passaram a ser sedentárias, a viver da agricultura e da pecuária, os mais fortes nessas sociedades se sobressaiam sob os demais, utilizando-se da força e violência para tomar terras e escravizar.

Com o passar dos anos, começou a surgir o Estado, este, começou a tomar para si este poder, para evitar a justiça privada e permitir a paz da sociedade, fazendo com que a justiça privada fosse substituída pela forma chamada de heterocomposição. Assim, a partir do século XVIII, essas mudanças foram consolidando-se na sociedade, surgindo então o Poder Judiciário, um poder estatal que regulamenta os direitos e deveres de uma sociedade, promovendo a ordem de uma sociedade, com a soberania da instituição, mas para que isso acontecesse, foi necessário que o homem abrisse mão de sua liberdade para o Estado, visando a sua segurança e a da sociedade

Conforme as sociedades começaram a se estabelecer e aperfeiçoar suas relações, começou a existir a justiça privativa, reflexo da Lei de Talião, ou seja, o ato de cada indivíduo agir por si só para obter seu direito. No entanto, quando começou a surgir à instituição estatal, logo o Estado tomou para si a função da jurisdição, pois percebeu-se a necessidade de conter a justiça privativa e vingativa, pois não haveria uma organização e nem tranquilidade social, se não houvesse a coerção estatal para lidar com os conflitos existentes, afinal, com a justiça privativa nunca foi possível identificar os direitos e deveres de cada uma das partes.

O início da história de quase toda a humanidade foi a mesma, foram vivenciadas por ancestrais nômades, que viviam de pesca e caça. Não havia classes sociais, estados ou hierarquias. As resoluções dos conflitos eram resolvidas dentro da comunidade pelas lideranças comunitárias, visando, apenas a proteção de possíveis perigos a coletividade, não existindo uma imposição de autoridade social, tendo em vista que as relações eram pouco complexas. Entretanto, com o passar dos anos, essas sociedades começaram a viver da agricultura e da pecuária, passando de nômades a sedentários, então, os mais fortes e ousados começaram a dominaram as terras, acumulando poderes e assim criando reinados e utilizando-se da força e 
da violência para escravizar povos derrotados em guerras de conquista, fazendo assim, a sua própria justiça e direitos. (VASCONCELOS, 2008, p. 22).

Então, surgiu o Poder Judiciário que detém e manipula a vingança privativa entre os homens, esta que tem como origem o interesse pessoal de cada indivíduo de obter de qualquer forma o seu direito infringido, tornando-se um monopólio de violência legitima, este poder estatal é uma técnica eficaz de prevenção a violência. Isso tudo funciona devido à independência que o Judiciário tem em suas decisões, sendo que as mesmas, não são discutidas e questionadas, é um serviço de todos e todos se inclinam diante de suas decisões. No entanto, o sistema jurídico que pode decidir sobre tudo, mas que não é totalmente eficaz acarreta em diferenças entre aquilo que o sistema da jurisdição diz que é, e o que na realidade faz. (MORAIS e SPENGLER, 2008).

Segundo Tartuce (2008, p. 80) o não cumprimento da norma legal permite ao Estado que vem no conflito substituindo às partes, fazer e aplicar a norma concreta à lide, exercendo o seu poder de comando, de maneira a eliminar a vingança privativa e como consequência desse poder exclusivo sobre a tutela de direito, obter a harmonia e a paz social. O direito a tutela jurisdicional pode ser provocado por todas as pessoas, desde que, uma norma esteja sendo infringida, ou seja, pretenda algo e encontre resistência, logo deverá utilizar-se do órgão judicial que permite e garante um processo com as garantias mínimas as partes e no final como resultado, obtenha-se a justiça.

Deste modo o Estado apareceu como um terceiro no conflito existente entre as partes, buscando a atuação do direito no caso concreto, regido pela imparcialidade e neutralidade. $\mathrm{O}$ Estado através do Poder Judiciário surge como este terceiro elemento no processo, mas não de forma igualitária comparado as outras partes litigantes, mas sim vem como uma parte que traz o direito concreto e o impõe para as partes, buscando através da lei a justiça real.

Quando demandamos judicialmente buscamos uma última palavra do juiz, fundamentada por lei, mas que diga as partes quem tem os reais direitos, ou quem ganha ou perde, ou seja, que decida sobre a lide. Assim, nota-se que, o Judiciário tem o poder de decidir sobre os litígios, mas não necessariamente lidar com sua causa. Isso por que cada conflito teus seus elementos e fatores específicos, então, a competência do Poder Judiciário limita-se a decidir os conflitos, e não eliminá-los, afinal decidir sobre um conflito existente não impede que outro surja com suas próprias características, ou que as relações e vínculos sejam extintos. (MORAES e SPENGLER, 2008).

Conforme Lemos e Alves (2013), a forma heterocompositiva da resolução de conflitos, é o modo onde um terceiro intervém evitando a violência, no caso o Estado, através do Poder 
Judiciário, que terá que decidir quem tem razão entre as partes. Na prática do Judiciário, há prazos, ritos e ordem processual que deverão ser cumpridas, de forma que apenas o conflito em si seja analisado, deixando-se de lado as causas desses conflitos, e na tentativa de igualar as partes, estas perdem sua identidade e apenas interessa o motivo pelo qual elas estão ali e a necessidade de que o conflito seja solucionado.

O Poder Judiciário visa a conflituosidade nos processos, sem dar a devida importância as causas desses litígios, que geralmente são fatos mais profundos e anteriores ao conflito que realmente chega ao conhecimento do Poder Judiciário, e como consequência a decisão dada pelo Juiz, que manifesta quem tem o direito no presente processo, acaba não colocando fim aquele conflito, isto por que sua causa inicial não foi tratada, e esse conflito pode voltar ao Poder Judiciário, e é o que acontece na maioria das vezes, o que acarreta em um aumento no volume de processos, tornando o trabalho do Judiciário mais moroso e difícil. (LEMOS e ALVES, 2013, p. 7).

Outro fator de destaque para a crise, é toda essa simbologia que existe em torno do Direito, como na linguagem rebuscada, seus ritos e mitos, a sua difícil compreensão de quem é leigo na matéria, aliada a questão do tempo processual e sua burocracia. "Toda esta estrutura burocrática, de cumprimento de prazos, de ritos e de limites que a jurisdição possui acaba por dificultar o acesso à justiça através do Judiciário.” (LEMOS e ALVES, 2013, p. 6). Tendo em vista esses fatores, surgiu a crise em razão da incapacidade do Poder Judiciário resolver as lides existentes e as que surgem, cada vez mais, no dia a dia, devido questões econômicas, políticas e sociais, ou seja, a resolução através do processo não tem demonstrado a capacidade de resolver o conflito.

Conforme Gorczevski (2007, p. 42) o Estado da mesma forma que tenta resolver questões, cria obstáculos para as mesmas. Destaca que, na maioria das vezes se dá mais importância ao formalismo do que aos próprios direitos da sociedade, o que acaba restringindo o direito do cidadão e não o resguardando.

Outros fatores que levaram à crise do Judiciário foi a Constituição Federal de 1988, que quis fornecer um amplo acesso à Justiça, entretanto, a ideia não saiu como planejada, pois o Poder Judiciário e seus órgãos prestadores de serviços, não conseguiram acompanhar o ritmo das demandas que a iniciativa trazida na Constituição Federal exigia. (TARTUCE, 2008).

O Poder Judiciário e toda sua estrutura estão ultrapassados e precisam ser modificados, pois o que foi planejado para ser preciso, com o passar do tempo, com as tecnologias, que foram desenvolvidas, as novas demandas existentes, afinal, atualmente, as pessoas tem buscado mais a Justiça, do que antigamente, tendo e vista que estão mais cientes dos seus direitos e diante

Barbarói, Santa Cruz do Sul, Edição Especial n.44, p.<220-237>, jul./dez. 2015 
disso o sistema do Judiciário se tornou ineficiente e inoperante, causando transtornos e contribuindo para a crise que atualmente está instalada no Poder Judiciário.

De importante destaque para a presente crise na Justiça também, é que toda essa lentidão que encontramos no Poder Judiciário, tem como responsáveis também a própria sociedade, pois não busca-se mais a solução dos conflitos de forma passível e fora da esfera da jurisdição, há uma tendência muito de forte de que qualquer conflito, por mais pequeno e irrelevante que seja, haja a procura do Judiciário.

A globalização muitas vezes nos remete apenas a ideia voltada à economia, ao mercado ou as culturas, mas, na verdade, a globalização altera várias outras questões. Sendo analisada como um fenômeno incontrolável, contra o qual, não podemos lutar, segundo Spengler (2010, p. 53), “o operador do Direito não pode perder de vista os avanços e retrocessos vertidos por esse processo na produção e na instituição da norma jurídica”.

Consequentemente essas questões levam a perda da soberania e da autonomia do Estado, o que acarreta a diminuição de seu poder de coação, resultando em uma crise de legitimidade. Pode-se observar que a globalização não atinge apenas a esfera econômica, de certa forma atinge todos os outros sistemas, inclusive causando uma flexibilidade e afrouxamento das funções do Estado. Por fim, apesar dos esforços para que o Poder Judiciário fosse eficiente na prestação de seus serviços à sociedade, seus órgãos não conseguem atender a demanda por Justiça. As pessoas humildes e mais carentes não tem acesso à Justiça, muitas nunca foram a uma audiência ou sequer conhecem um Fórum, isso demonstra a grande distância que uma parte da sociedade tem desse serviço estatal. (SILVA, 2008).

Para Spengler (2013) a crise do Estado que atinge o Poder Judiciário, reflete na falta de respostas satisfatórias das instituições estatais para a sociedade, frustrando não só as expectativas criadas pela criação de novos direitos como pela condição social e econômica dos conflitantes, e como consequência gerando a indeterminação e a indefinição que acabam provocando o enfraquecimento da certeza jurídica.

Diante da impossibilidade de tratar de todos os conflitos de forma adequados que hoje chegam à Justiça, devido a todos os fatores já supracitados, ocorre um descompasso de forma que traz uma perda do poder do Estado e um desprestígio do Poder Judiciário. Vive-se um momento de complexidade na Justiça, tendo em vista que há um aumento extenso e intenso de reivindicações de acesso à Justiça e em resposta temos um sistema ineficaz e de mecanismos insuficientes para satisfazer as demandas existentes. (MORAIS e SPENGLER, 2008, p. 106).

Demonstra-se de forma clara que o Poder Judiciário está sobrecarregado e que são necessárias medidas para que aconteçam mudanças, diante dessa situação, têm-se as seguintes

Barbarói, Santa Cruz do Sul, Edição Especial n.44, p.<220-237>, jul./dez. 2015 
soluções: implementar uma profunda reforma processual (que já vem acontecendo), ou, resgatar da sociedade alternativas extrajudiciais para que alguns conflitos não precisem chegar ao Judiciário como um processo litigioso, mas que haja meios para que conflitos sejam solucionados como a utilização de conciliação, mediação e arbitragem. (JUNIOR, 2008, p. 225).

Como já supracitado o Poder Judiciário foi criado para regular as relações e impedir a violência privada, delimitando assim o poder dos indivíduos da busca de sua própria justiça, sem normas e leis. Entretanto, este órgão estatal que foi criando para solucionar os conflitos está em crise, e é notável os problemas que enfrentamos para a obtenção de respostas das nossas demandas postuladas. Diante dessa realidade qual seriam os meios, soluções para, no mínimo, amenizar tal situação? Um dos possíveis meios são as medidas alternativas a Jurisdição, que são uma solução mais rápida e barata ao sistema e é considerada está a principal maneira de “desafogar" o Judiciário de processos, que poderiam se resolver tratando diretamente sua causa.

\section{Alternativas extrajudiciais frente à crise do Poder Judiciário: apontamentos}

Uma vez tendo sido apresentada toda a situação da crise que vem sendo enfrentada pelo Poder Judiciário, necessário se faz a apresentação, em contraponto, de formas alternativas à jurisdição tradicional. Neste aspecto, é inevitável que o surgimento de alternativas à jurisdição advieram da necessidade social por métodos para a resolução de conflitos fora da esfera do Poder Judiciário, que se encontra com dificuldades no seu sistema, tornando-se muitas vezes insuficiente e sobrecarregado de conflitos sociais que acarretam numa desconfiança e insatisfação com este poder estatal.

Segundo Lemos a Alves (2013) diante dessas razões, as formas alternativas à jurisdição tradicional têm se mostrado eficientes, pelo fato de lidarem com a causa e pela sua preocupação e atendimentos aos episódios conflitivos. Segundo Spengler (2010, p. 97) "A falta de eficiência e legitimidade estatal faz também com que o cidadão comum busque outras instâncias de tratamento de conflitos, alternativas ao Direito legislado e ao Poder Judiciário.” E essa busca, demonstra-se comum perante a crise do Judiciário, surge como resposta da sociedade, que necessita de meios eficientes e menos danosos a resolução de conflitos.

Essas novas abordagens para a resolução de conflitos, tem como um dos seus aspectos, encontrar fatores em comuns nos interesses das partes da demanda. Nas alternativas da jurisdição o objetivo é que, ambas as partes ganhem com o fim do conflito, de modo em que os 
conflitantes desejem compor uma situação mais favorável a eles, através de conversações e debates. (TARTUCE, 2008).

Segundo Lemos e Alves (2013) nas alternativas à jurisdição as partes participam da solução do conflito. "Dessa forma, é preciso que haja uma transformação da relação existente no âmbito do processo, que é de "eu/tu”, para uma relação "entre-nós" (relações de alteridade).” Nessas relações há uma retomada do conflito pelas partes, e estas se tornam responsáveis pelas escolhas feitas para a sua resolução. Diante disso o conflito é solucionado pelas próprias partes, sem que haja a intervenção de um terceiro, visando reconstruir os laços sociais que foram extintos pelo conflito.

Ainda não há uma cultura na efetiva utilização das alternativas de jurisdição, todavia importante destacar a criação da Resolução $n^{\circ} 125$ do Conselho Nacional de Justiça, que visa o estímulo das pessoas para que busquem a solução dos conflitos, bem como o recepcionamento pelo novo Código de Processo Civil sobre a alternativa de mediação, o que demonstra o quanto esta alternativa vem sendo eficiente na resolução de conflitos, ou seja, diante das suas características de celeridade, economia processual, informalidade e flexibilidade, pode-se observar um crescimento desses meios alternativos de resolução de conflitos no país.

\section{O instituto da Arbitragem como mecanismo alternativo}

A arbitragem é disciplinada pela Lei $\mathrm{n}^{\circ}$ 9.307/96, e é o método que mais se assemelha a jurisdição tradicional, pois nesta alternativa, há um processo igual ao judicial, onde as partes atacam e defendem, e a decisão também é imposta, ou seja, é um terceiro que decide o conflito. Contudo, se difere do Poder Judiciário por que neste método são as próprias partes que escolhem o árbitro, diferente da jurisdição tradicional, e a forma do procedimento a ser utilizada, tornado a arbitragem um instituto legítimo e democrático. Ademais, se permitido pelas partes, o árbitro poderá decidir com base na equidade, nos costumes e usos, não limita-se as formas e regras expressas de direito como na jurisdição tradicional. (AMARAL, 2008, p. 02)

Assim, a arbitragem é um meio pelo qual o Estado não intervém diretamente no conflito para resolvê-lo, permitindo que uma terceira pessoa o faça, seguindo e observando um procedimento com algumas regras legais, e obtendo-se uma decisão idêntica à de uma sentença judicial, ou seja, as partes ao optarem por essa estratégia de tratamento de conflitos, afastam a jurisdição estatal, mas método que é reconhecido e regulado pelo Estado. (MORAIS e SPENGLER, 2008). Para Katzwinkel (2008, p. 78) o instituto da arbitragem possui eficiência e segurança para a solução de conflitos, através dos juízes arbitrais, especializados em várias

Barbarói, Santa Cruz do Sul, Edição Especial n.44, p.<220-237>, jul./dez. 2015 
áreas, sendo que, quando escolhidos pelas partes, assumem o compromisso de atuar de forma imparcial e com liberdade.

Para Silva (2008, p. 22) "A escolha pela via arbitral decorre da vontade das partes, que também têm ampla liberdade para convencionar quais as regras serão aplicadas na arbitragem [...]." A opção pelo método alternativo de arbitragem é opcional às partes, que buscam uma resolução mais rápida do conflito. A decisão será proferida por terceiro, pessoa de confiança das partes e por elas escolhido. Este árbitro mesmo sem poder estatal, profere a decisão com força vinculante. Esta sentença arbitral tem eficácia de título executivo judicial, e em caso de não cumprimento, a parte irá se valer do aparato estatal executivo. (TARTUCE, 2008).

Outras considerações importantes que devem ser feitas sobre essa alternativa de jurisdição é que o árbitro pode tanto de ofício como a requerimento das partes ouvir testemunhas, designar perícias ou determinar outras provas. Entretanto, não cabe ao juízo arbitral executar suas sentenças, esse procedimento deve ser realizado através do Poder Judiciário (SILVA, 2008).

Segundo Tartuce (2008, p. 76) a arbitragem se firmou como um método eficiente para gerar uma decisão cabível na resolução dos conflitos, envolvendo até direitos patrimoniais disponíveis, ou seja, a arbitragem tem sido utilizada pra dirimir conflitos das mais variadas índoles e diferentes graus, até mesmo os que versão sobre direitos indisponíveis, mas que é possível que haja certos pontos patrimoniais negociáveis o que permite que as partes submetam o impasse à decisão de um árbitro.

Assim, considera-se o instituto da arbitragem como um modo útil e democrático, pois há a autonomia das partes para a escolha do árbitro para a resolução do conflito, como também podem escolher ou não a utilização desse método alternativo, e mesmo não sendo proferida uma decisão pela Justiça tradicional, com o não cumprimento há meios de exigi-la, demonstrando ser uma alternativa com real eficácia.

\section{A Mediação como perspectiva de resolução de conflitos}

A Lei n ${ }^{\circ} 13.140$ de 26 de junho de 2015, dispõe sobre a mediação entre particulares como meio de solução de controvérsias e sobre a autocomposição de conflitos no âmbito da administração pública. E conforme seu artigo $1^{\circ}$, dispõe sobre a mediação como meio de solução de controvérsias entre particulares e sobre a autocomposição de conflitos no âmbito da administração pública. Considerando-se mediação a atividade técnica exercida por terceiro imparcial sem poder decisório, que, escolhido ou aceito pelas partes, as auxilia e estimula a

Barbarói, Santa Cruz do Sul, Edição Especial n.44, p.<220-237>, jul./dez. 2015 
identificar ou desenvolver soluções consensuais para a controvérsia. A Lei da Mediação, conforme expressão do artigo $2^{\circ}$, veio regular o meio de solução de controvérsias e a autocomposição, sendo orientada pelos seguintes princípios: I - imparcialidade do mediador; II - isonomia entre as partes; III - oralidade; IV - informalidade; V - autonomia da vontade das partes; VI - busca do consenso; VII - confidencialidade; VIII - boa-fé.

Nesse método as próprias partes acham as soluções, o mediador apenas busca facilitar esse instrumento, procurando com suas técnicas o melhor entendimento das partes sobre o processo de mediação. É a alternativa privada de resolução de conflitos, voluntária e confidencial. Com a utilização dessa alternativa de jurisdição o indivíduo retoma o controle da sua vida pessoal e consegue com a resolução dos conflitos a necessária liberdade e paz social (SILVA, 2008).

Segundo Silva (2004, p.15) "no processo de mediação não há qualquer preocupação quanto ao formalismo. A mediação é extremamente útil para muitos tipos de demanda e partes". O objetivo dessa alternativa extrajudicial na resolução de conflitos é a busca por um acordo entre as partes, utilizando-se de meios como o da comunicação, do direito, da psicologia, entre outros.

É uma forma pacífica de resolução de conflitos já que vem das partes a vontade de firmar o acordo. Todavia, nem sempre as pessoas conflitantes conseguem sozinhas estabelecer um diálogo que permita o entendimento. Nesse aspecto mostra-se importante a mediação, com a presença de uma terceira pessoa que auxilia as partes, aproximando-as, estabelecendo o diálogo, procurando identificar os pontos controvertidos e ajudar no acordo, mas sem dar sugestões. A mediação não é um instituto jurídico, apenas uma técnica de resolução de conflitos, e poderá ser sempre utilizada nos conflitos que não incidam sanções penais e que não sejam contra a moral e bons costumes, sendo necessário sempre exista igualdade entre as partes. Várias são as denominações para a mediação, muitos procuram diferenciá-la da conciliação (outra alternativa à jurisdição), mas não definem critérios claros e objetivos de distinção (SILVA, 2008).

É necessário para que a mediação funcione, a boa-fé e vontade das partes, e para que o acordo realizado na mediação seja executado é preciso que seja homologado pelo Judiciário, mas importante frisar que às vezes a mediação não comporta a intensidade e tamanho do conflito, ou seja, há situações que não podem ser mediadas. (MORAIS e SPENGLER, 2008). A utilização dessa alternativa à justiça tradicional vem sendo expandida de forma expressiva, no início muito utilizada na esfera internacional, entretanto, nosso país tem apresentando um grande crescimento há essa prática, ou seja, já é expressivo o uso da mediação e da arbitragem,

Barbarói, Santa Cruz do Sul, Edição Especial n.44, p.<220-237>, jul./dez. 2015 
meios que facilitam a resolução de conflitos, contribuindo-se para a diminuição da demanda judicial na esfera tradicional.

$\mathrm{Na}$ mediação não se aplicam as regras processuais, os princípios que atuam na área judicial de forma apenas a resolver o conflito. O resultado final, busca corresponder as características dos próprios participantes sem estarem vinculados a precedentes anteriores. Com a ajuda do mediador, as partes expõem suas necessidades ou qualquer outro fator que consideram relevante. A diferença entre a mediação e o processo judicial é que na mediação não se discute quem ganha ou quem perde, mas sim, procura-se estabelecer uma solução prática que seja satisfatória aos participantes. (GORCZEVSKI, 2007).

Conforme Morais e Spengler (2008, p. 137) não cabe ao mediador oferecer a solução do conflito as partes, porém, este deve dar a manutenção e a orientação ao procedimento, pois se a mediação tem como objetivo a pacificação do conflito, é competência do mediador alertar as partes quando a decisão se afaste do caráter da mediação que é de pacificar e reaproximar as partes.

Segundo Morais e Spengler (2008), o objetivo da mediação é em relação aos problemas relativos às questões do quotidiano, como divergência entre membros de instituições de ensino e lazer, discussões entre vizinhos e familiares, ou seja, questões que podem ser tratadas de forma pacífica entre as partes sem a necessidade da busca do Judiciário, tendo em vista que na mediação com o auxílio do terceiro de forma parcial, o mediador, busca-se produzir decisões consensuais entre as partes, com a ajuda do direito.

Segundo o Spengler (2013), enquanto o Judiciário não aceita o conflito e apenas determina quem tem razão, a mediação procura lidar com o desacordo, dando tempo e espaço para a discussão do mesmo, o que não acontece no Judiciário, que possui seus ritos, prazos e tempo diferenciado. Desta forma, fica claro que a jurisdição tradicional e a mediação tem linguagens diferentes, são autônomos, mas há a necessidade da obtenção de conexões entre eles, mas cada um mantém sua autonomia de linguagem.

\section{A Conciliação enquanto alternativa prospectiva de solução de conflitos}

Segundo Leite (2008) a conciliação busca valorizar o potencial das pessoas, para que estas possam decidir sobre suas próprias questões, mas também sua própria dignidade, honra, liberdade, valores que muitas vezes se perdem no meio dos conflitos. A conciliação já não é mais apenas letra de Lei, está muito presente no cotidiano dos operadores do Direito, estes que devem estar preparados e aptos a exercer a habilidade conciliatória, para lidar com a realidade.

Barbarói, Santa Cruz do Sul, Edição Especial n.44, p.<220-237>, jul./dez. 2015 
É também uma forma alternativa de resolução de conflitos fora da esfera da justiça tradicional, administrada por um conciliador, que tem como função aproximar as partes, controlar as negociações, sugerir propostas e até formulá-las, demonstrando as desvantagens e vantagens, sempre buscando pôr em acordo e harmonizar duas ou mais pessoas em conflito. (TARTUCE, 2008).

Esse movimento tem o objetivo de promover a ideia de que o entendimento das partes para a resolução do conflito é a melhor maneira de realmente se chegar à extinção do conflito, através da mudança de atitudes de todos os operadores do Direito, o que só traz benefícios com a satisfação das partes e menor tempo na solução dos conflitos. E como na mediação, há melhora no relacionamento entre as partes, levando a paz social na comunidade onde as mesmas estão inseridas. (SILVA, 2008).

Para Gorczevski (2007), compreende-se como conciliação o método onde um terceiro busca o entendimento das partes e a solução do conflito, não sendo a mediação ou arbitragem. Este terceiro restringe-se aos aspectos materiais e objetivos do desacordo. A conciliação pode ser aplicada pela própria vontade das partes ou por imposição legal, tanto na fase pré-processual como no decurso de um processo. Para Vasconcelos (2008) a conciliação é um tipo de mediação focada no acordo. Apropriada sua utilização para situações de relações de consumo, para relacionamento que não objetivam mais a relação, apenas definir interesses materiais. É bastante utilizada pelo Poder Judiciário de forma intuitiva. Em relação ao procedimento, considera-se a conciliação mais rápida que a mediação; porém menos eficaz.

Segundo Spengler (2013), para que a conciliação dê certo, além do diálogo entre as partes, necessário que ambas conheçam a razão do conflito, e mais do que isso, haja concessões recíprocas para que possa se estabelecer um acordo. Essas concessões recíprocas, muitas vezes não satisfazem as partes, e não solucionam todos os pontos do conflito, e isso pode fazer com que este mesmo conflito volte a existir e, até mesmo, com mais força. A conciliação não tem como objetivo estabelecer a real verdade dos fatos na solução do conflito, e às vezes, esses pontos não solucionados e também obscuros, fazem com que a conciliação não se torne eficaz e o conflito volte a ocorrer.

Para Gorczevski (2007), a conciliação extrajudicial, chamada também de préprocessual, procura resolver o conflito antes deste realmente chegar ao Judiciário como um processo tradicional, ocorre fora da esfera judicial e pode surgir de um acordo entre as partes, com ou sem auxílio de terceiros ou pode surgir como uma condição pré-processual e obrigatória para alguns tipos de processos. Na conciliação extrajudicial o terceiro apenas procura realizar o acordo, de forma que a decisão encontra-se com as partes. Seu objetivo é tentar acalmar os

Barbarói, Santa Cruz do Sul, Edição Especial n.44, p.<220-237>, jul./dez. 2015 
temperamentos extremos para que seja possível a composição do acordo, mas a solução depende sempre da vontade das partes e não do conciliador. Não exige formas e nem procedimentos, desde que as partes se encontrem satisfeitas e o acordo seja o resultado final. A conciliação obrigatória e pré-processual é utilizada no Uruguai, onde a sua Constituição estabelece tal obrigatoriedade, no Brasil apesar de várias tentativas, ainda não há essa prerrogativa.

Para Silva (2008), a conciliação é a forma que tem mais potencialidade e a mais pacífica para a resolução de conflitos. O início da conciliação foi uma experiência simples e de sucesso. Apesar de ainda ter obstáculos e aperfeiçoamentos a serem realizados, o que será alcançado com o tempo e com a colaboração daqueles que usufruírem desta alternativa a jurisdição estatal. Se o Poder Judiciário e outros Poderes incentivassem essa ideia, toda uma estrutura técnica e gerencial existiria e a implementação deste instituto seria uma consequência. No mais, a conciliação baseada na simplicidade tem um forte propósito de enfrentar os obstáculos processuais, sendo uma forma extrajudicial, evitando que mais acúmulos de processos, diante de uma insuficiência do poder estatal.

Necessário ressaltar que a conciliação ganha cada vez mais espaço na resolução de conflitos, isso por que, busca-se com essa alternativa soluções mais rápidas aos conflitos e maior predominância das vontades das partes, dentro dos limites da legislação. A função do conciliador sendo realizada, o sigilo das decisões e o vínculo pacificador fazem com que se torne uma medida eficaz para as resoluções de diversos conflitos. Essa alternativa à jurisdição já é aceita, apesar de algumas oposições. (GORCZEVSKI, 2007).

Por fim, fica evidente a importância dessas alternativas extrajudiciais que vem em contraponto e como resposta ao Poder Judiciário. Se todos os conflitos que chegam até estas modalidades de solução de conflitos, fossem até os tribunais, levariam anos para serem solucionadas, sendo que as partes teriam que manter os gastos de tudo isso, além do desnecessário desgaste que acomete as partes litigantes. Outro destaque, que faz toda a diferença é que, na esfera judicial um juiz togado exercerá o poder de decisão, já nessas alternativas como arbitragem, mediação e conciliação, as partes de comum acordo poderão indicar alguém que conduzirá a questão. Essas modalidades extrajudiciais, cada vez mais, ajudam a desafogar o Poder Judiciário, sendo incontestável na quantidade de processo. (SILVA, 2008). 


\section{Considerações Finais}

Em linhas conclusivas, parece-nos que para a construção de uma sociedade ética e solidária, em que pese aos cidadãos participar dos processos democráticos - são necessários mecanismos de co-gestão participativa e democrática para que haja um verdadeiro reconhecimento nas esferas cívicas. Portanto, a busca por uma democracia participativa, regida pelos princípios de liberdade, igualdade e justiça social, continua sendo o horizonte histórico buscado, e a utopia para a humanidade, afinal, a utopia, mesmo quando parece afastar-se tem o condão de nos obrigar a caminhar para alcançá-la. O objetivo destes mecanismos alternativos extrajudiciais é encontrar pontos em comum entre as partes, de maneira que elas queiram compor um acordo favorável para ambos, através de debates e conversações, ou seja, a resolução do conflito surge das partes, sem a intervenção do Estado, apenas de um terceiro, cujo papel será de facilitar o diálogo, e não ditar uma decisão/sentença. Nessas alternativas o conflito é retomado, e as partes tornam-se responsáveis pelas escolhas feitas, esses métodos também visam reconstruir laços sociais que foram extintos pelo conflito. As características desses mecanismos é a celeridade, economia processual, informalidade e flexibilidade, diante dessas características observa-se um crescimento desses meios alternativos como, por exemplo, a arbitragem, mediação e conciliação. Percebe-se um importante papel realizado pelas alternativas extrajudiciais junto às demandas e a crise do Poder Judiciário, afinal, são políticas de pacificação de conflitos sociais.

\section{REFERÊNCIAS}

AMARAL, Antonio C. Rodrigues. Mediação, arbitragem e conciliação. (Grandes temas da atualidade, v. 7). Rio de Janeiro: Forense, 2008.

OSTA, Ademar Antunes da. Cidadania e direitos humanos no marco do constitucionalismo. In: COSTA, Marli M. M. da. Direito, cidadania e políticas públicas II. Porto Alegre: Imprensa Livre, 2007.

GORCZEVSKI, Clovis. Jurisdição paraestatal: solução de conflitos com respeito à cidadania e aos direitos humanos na sociedade multicultural. Porto Alegre, 2007.

JUNIOR, José A. de Oliveira. Mediação, arbitragem e conciliação. (Grandes temas da atualidade, v. 7). Rio de Janeiro: Forense, 2008.

KATZWINKEL, Edgard. Mediação, arbitragem e conciliação. (Grandes temas da atualidade, v. 7). Rio de Janeiro: Forense, 2008. 
MARTINS, Pedro A. Batista. Mediação, arbitragem e conciliação. (Grandes temas da atualidade, v. 7). Rio de Janeiro: Forense, 2008.

MORAIS, José L. B. de; SPENGLER, Fabiana Marion. Mediação e arbitragem: alternativa à jurisprudência. 2 ed. Ver. E ampl. Porto Alegre: Livraria do Advogado Editora, 2008.

SCHMIDT, João Pedro. Para entender as políticas públicas: aspectos conceituais e metodológicos. In: REIS, Jorge R.; LEAL, Rogerio G. Direitos Sociais e Políticas Públicas: desafios contemporâneos. Tomo 8. Santa Cruz do Sul: Edunisc, 2008.

SILVA, Antônio Hélio. Mediação, arbitragem e conciliação. (Grandes temas da atualidade, v. 7). Rio de Janeiro: Forense, 2008.

SILVA, João Roberto da. A mediação e o processo de mediação. São Paulo: Paulistanajur, 2004.

SPENGLER, Fabiana Marion. Da jurisdição à mediação: por uma outra cultura no tratamento de conflitos. Ijuí: Ed. Unijuí, 2010, 432 p.

Fundamentos políticos da mediação comunitária. Ijuí: Ed. Unijuí, 2012, 272 p.

TARTUCE, Fernanda. Mediação nos conflitos civis. Rio de Janeiro: Forense. São Paulo: Método, 2008.

VASCONCELOS, Carlos Eduardo de. Mediação de conflitos e práticas restaurativas. São Paulo: Método, 2008.

ZAFFARONI, Eugenio Raúl. Poder judiciário: crise, acertos e desacertos. São Paulo, ed. Revista dos Tribunais, 1995.

http://www.cnj.jus.br///images/atos_normativos/resolucao/resolucao_125_29112010_160920 14165812.pdf

\section{Sobre as autoras:}

Francielli Silveira Fortes é Mestre em Direito. Membro do Grupo de Pesquisa Direito, Cidadania e Políticas Públicas do Programa de Pós-Graduação - Mestrado e Doutorado em Direito da Unisc, vinculado ao CNPq. Professora do Departamento de Direito da UNISC. Mediadora Judicial do Centro Judiciário de Solução de Conflitos e Cidadania (CEJUSC) no Fórum da Comarca de Santa Cruz do Sul. Endereço eletrônico: franciellifortes@ hotmail.com

Natália Luiza Fetzer é Bacharel em Direito pela Universidade de SANTA Cruz do Sul. Integrante do Grupo de Pesquisa Direito, Cidadania e Políticas Públicas, realizado pelo Programa de Pós-Graduação - Mestrado e Doutorado da UNISC. Endereço eletrônico: naty9@hotmail.com 